was an obvious mechanical cause. If flow was still unsatisfactory after attempted declotting, clots were occasionally dislodged or vessel spasm was overcome by the slow infusion of a solution of 20,000 international units of heparin in $500 \mathrm{ml}$. of saline. Angiograms were performed by the injection of 3 to $4 \mathrm{ml}$. of $60 \%$ Urografin via the open end of the cannula (Fig. 3) in resistant cases. An attempt was then made to dissolve visualized clot by the injection of 250,000 units of streptokinase (Kabikinase) in $2 \mathrm{ml}$. of sterile water into the cannula, which was clamped for 30 minutes. Flow was restored by this procedure on four of the seven occasions on which it was used. Where declotting was not successful, one limb or occasionally both limbs of the shunt were replaced. Anticoagulants were used systemically after recurrent episodes of clotting, and were particularly valuable where there was evidence of phlebitis.

Twenty episodes of infection occurred in 8 of the 11 patients, being secondary to skin erosion over the venous loop on seven occasions. Nine of these infections led to loss of cannulae. The causative organism was Staphylococcus atreus, except in twwo cases where a $\beta$-haemolytic streptococcus was isolated. Septicaemia secondary to cannula infection occurred in two patients, and was successfully treated by antibiotics without loss of the cannulae. Nasal, throat, and perineal swabs were taken before insertion of cannulae and at intervals thereafter. Attempts were made to eradicate nasal and skin carriage of staphylococcus, but persistent carriers were treated with lincomycin (Lincocin), cloxacillin (Orbenin), or methicillin (Celbenin) from the time of insertion of cannulae for periods of two to four weeks. If infection became established and persisted in spite of antibiotic therapy, the cannulae were removed and another limb was cannulated next day under antibiotic cover. In four patients with infected arterial cannula wounds persistent bleeding occurred, and was found to be due to false aneurysm formation. Bleeding was controlled by proximal ligation of the vessel and removal of the cannula. A more detailed analysis of these infections, with particular refer- ence to phage typing and the source of the organisms, will be presented elsewhere.

\section{Summary}

Two years' experience with the Silastic-Teflon arteriovenous cannula system in the management of patients with chronic renal failure by intermittent haemodialysis is reported. The mean arterial cannula survival time was 7.6 months and the venous survival time 7.3 months. Careful attention to a number of apparently minor points during insertion improved cannula survival. The two limiting factors in cannula life were clotting and infection. Declotting was usually achieved if the patient attended within three hours. If flow was unsatisfactory after using standard declotting procedures angiography was performed and streptokinase infused into the cannula. Flow was restored in four out of seven cannulae by this method. The causative organism was Staphylococcus aureus in almost all the cases of infection. Antibiotics were used both prophylactically and therapeutically, but cannula removal and replacement in another limb was necessary in 9 out of 20 cases of infection.

We wish to thank Dr. J. S. Robson and Professor M. F. A. Woodruff for permission to report on cases under their care, and for their advice and encouragement; Dr. R. W. Tonkin for the bacteriological investigations; Dr. D. J. Sinclair and Dr. T. A. S. Buist for the angiographic studies; and Mr. A. Patterson for the photographs.

\section{REPERENCES}

Clark, P. B., and Parsons, F. M. (1966). Brit. med. F., 1, 1200 Hegstrom, R. M. Quinton, W. E., Dillard, D. H., Cole, J. J., and Scribner, B. H. (1961). Trans. Amer. Soc. artif., intern. Organs, 7, 47.

Pendras, J. P., and Smith, M. P. (1966). Ibid., 12, 222.

Quinton, W. E., Dillard, D. H., Cole, J. J., and Scribner, B. H. (1962).

Ibid., 8 , 236 . C., Rottka, H., and Shaldon, S. (1964). Proceeding of the European Dialysis and Transplant Association, 1, 271.

\title{
Prevention of Urinary Infection by Means of Closed Drainage into a Sterile Plastic Bag
}

\author{
W. A. GILLESPIE,* M.D., F.C.PATH., F.R.C.P.I., M.R.C.P. ; G. G. LENNON, † M.B., CH.M., F.R.C.O.G., M.M.S.A. \\ K. B. LINTON,ł PH.D., B.SC.; G. AUDREY PHIPPEN,§ S.R.N.
}

Brit. med. F., 1967, 3, 90-92

If urinary infection is to be avoided when indwelling catheters are used, bacteria must be prevented from entering the bladder or destroyed soon after they enter. Infection through the catheter may be prevented by drainage into a closed sterile container. Passage of bacteria between catheter and urethral wall (an important route of infection in females) may be diminished by immobilizing the indwelling catheter. Application of these measures, together with disinfection of the urethra and bladder when catheters were inserted, reduced the postoperative urinary infection rate in gynaecological patients from 97 to $13 \%$ (Gillespie, Lennon, Linton, and Slade, 1962, 1964).

Drainage bottles containing formalin, which were used in these studies, were troublesome to prepare. We report here the

- Professor of Clinical Bacteriology, University of Bristol. ' + Professor of Obstetrics and Gynaecology, University of Bristol. — Lecturer in Medical Bacteriology, University of Bristol.

Ward Sister, United Bristol Hospitals.

Supplied by Eschmann Bros. and Walsh Ltd., Shoreham-by-Sea, Sussez. results obtained with the use of closed sterile plastic bags instead of bottles.

\section{Materials and Methods}

Meredith|| urine drainage bags were used after 1 January 1965 (see Photograph). The drainage tube, which is sealed into the bag, ends in a valve, a flat collapsible plastic tube. Any increase of pressure in the bag closes the valve and prevents reflux of urine into the tube.

The patients, all of whom had uninfected urine initially, underwent gynaecological operations similar to those in the previous investigation and were treated in the same ward. Their bladders were drained by indwelling Foley catheters for four days after operation; during the next few days most patients were catheterized intermittently, between one and six times in all, to remove residual urine. Except for the substitution of 
plastic bags for bottles, the postoperative treatment was the same as before (Gillespie et al., 1964) ; Foley catheters were immobilized by fitting plastic sponge collars which were smeared twice daily with chlorhexidine (Hibitane) obstetric cream. Chlorhexidine was also used to disinfect the urethra and bladder every time a catheter was inserted.

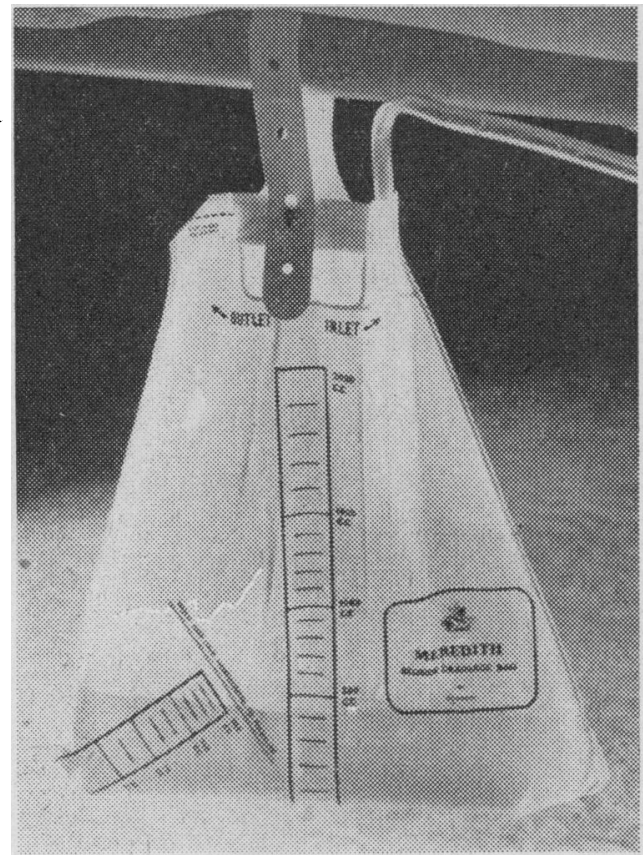

Meredith plastic drainage bag with non-return valve.

\section{Results}

The results of the present and previous trials are summarized in Table I. The first results with plastic bags were disappointing ; more than half the patients became infected. The fault, however, was probably not in the valve or bag. Culture of urine samples taken simultaneously from the tube above the valve and from the bag showed that bacteria were rarely present in the bag before they appeared in the tube. It seemed likely that bacteria entered the catheter when the drainage tube was disconnected to change the bag when it became full. The point of disconnexion, where the tube joined the catheter, was under the bedclothes, near the patient, and therefore liable to heavy contamination. Moreover, plastic tubes lack elasticity and are difficult to connect and disconnect neatly. Accordingly, several precautions were taken to prevent entry of bacteria when changing bags. The plastic drainage tube was cut short a few inches above the bag and connected to the catheter by a sterile rubber tube. When the bag became full it was detached from the lower end of the rubber tube, a less heavily contaminated site and farther from the patient. The infection rate fell to $17 \%$ (Table I).
Though the modifications which caused this improvement probably would not be practicable in a busy ward, the results showed the danger of infection by bacteria entering when full bags were detached from the catheter. The next stage in the trial, therefore, was to use one bag for each patient, as a reservoir, and never change it. The drainage tube was connected to the catheter before the patient left the theatre. When the bag became full it was emptied through an opening distal to the valve, made by cutting off a corner opposite the point of entry of the drainage tube (see Photograph). The bag was tilted and the urine poured into a pail containing phenolic disinfectant. The corner of the bag was then sealed with waterproof tape until the next emptying. Seventy-four patients were treated by reservoir drainage ; 17 . $23 \%$ ) became infected (Table I).

Study of the responsible bacteria suggested that most infections occurring during the period of full precautions were caused by self-infection, whereas previously, with open drainage and no special precautions, cross-infection was very common. During the initial period there were many mixed infections by Klebsiella, Proteus vulgaris, Pr. rettgeri, Pr. mirabilis, and Escherichia coli (Table I).

Many strains of Klebsiella and Proteus were resistant to several antibiotics and probably indicated cross-infection (Gillespie, Linton, Miller, and Slade, 1960). When the infection rate fell after the introduction of precautions, most of the resistant bacteria disappeared. Most of the infections that still occurred were caused by $E$. coli and $\operatorname{Pr}$. mirabilis, which probably came from the patients themselves. Support for this belief was obtained by testing Pr. mirabilis isolates by Dienes's method (Dienes, 1946 ; Kippax, 1957). Of 12 isolates which were examined, 10 were distinct from each other. Hence most infections during the period of full precautions were probably due to a fault in the management of the catheter and not in the method of drainage. The recent preponderance of Pr. mirabilis may be due to the fact that it is less sensitive than $E$. coli to chlorhexidine (Table II).

\section{Discussion}

Several methods may be used to prevent infection during indwelling catheterization. All should incorporate some form

TABLE II.-Minimum Inhibitory Concentrations of Chlorhexidine for the Strains of $E$. coli and Pr. mirabilis from Urine Infected During the Use of Plastic Reservoir Drainage Bags

\begin{tabular}{c|c|c}
\hline M.I.C. of Chlorhexidine & E. coli & Pr. mirabilis \\
\hline $1 / 2,000$ & 0 & 2 \\
$1 / 4,000$ & 0 & 4 \\
$1 / 8,000$ & 0 & 4 \\
$1 / 16,000$ & 0 & 2 \\
$1 / 32,000$ & 0 & 0 \\
$1 / 64,000$ & 0 & 1 \\
$1 / 128,000$ & 0 & 0 \\
$1 / 256,000$ & 0 & 0 \\
$1 / 512,000$ & 3 & 13 \\
\hline Total & 3 & 0 \\
\hline
\end{tabular}

TABLE I.-Incidence and Causative Bacteria of Postoperative Urinary Infection in Gymaecological Patients, in Relation to Method of Treatment

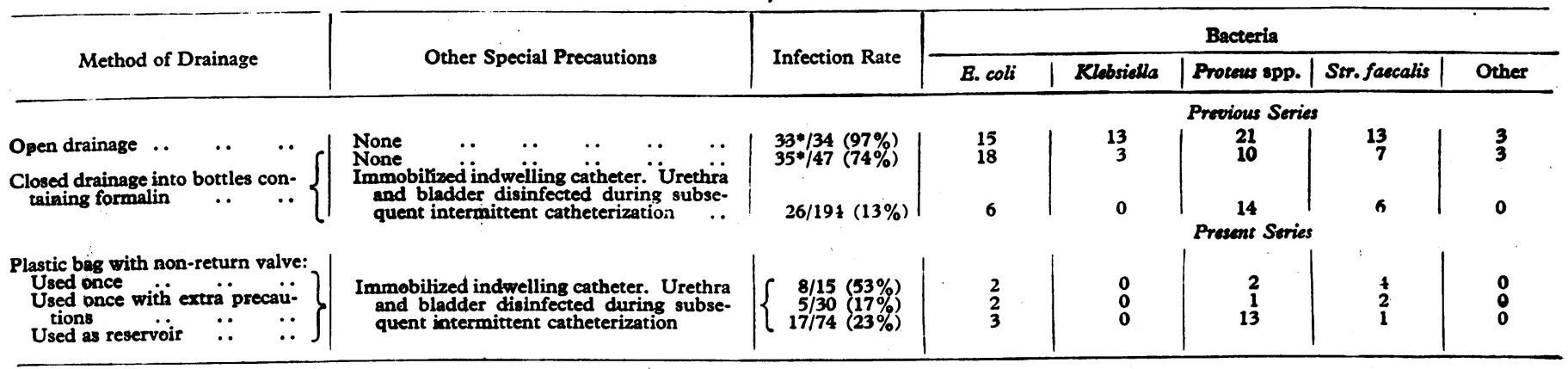

\footnotetext{
- Some infections were mixed.
} 
of closed sterile drainage. Disposable sterile plastic bags are convenient, but many that have appeared on the market are unsatisfactory, since though they are sterile initially they become contaminated during use (Roberts, Linton, Pollard, Mitchell, and Gillespie, 1965). The bag should remain closed during use and should be designed to prevent reflux of urine into the drainage tube. This is important, since small numbers of bacteria may pass from the urethra to the bladder and thence to the bag, where they may multiply and, if reflux is allowed, re-enter the bladder in large numbers. The longer the period of drainage the greater the chance of infection arising in this way. It would be dangerous to place a disinfectant in a nonrigid receptacle, since compression might force it back into the bladder. Kunin and McCormack (1966) described the use of a reservoir drainage bag without a valve. However, it is diffcult to compare their results with ours, because few of their patients were gynaecological. Moreover, most of their patients received antimicrobial drugs, whereas none of ours did. Several drainage bags with valves have appeared on the market. We have found the valve of the Meredith bag to be the most efficient of those we have seen. In laboratory tests in which the bag was filled with contaminated urine it was impossible to force bacteria back through the valve by compressing the bag. However, when a partly filled bag was laid gently on the floor, and not compressed, a slow reverse flow could sometimes be detected. In practice, such slow leakage would be opposed by the flow of urine, which also would oppose the movement of motile bacteria.

Perhaps the greatest risk of infection during closed drainage is by bacteria that gain access to the catheter when the receptacle is detached because it is full. It follows that if reflux can be avoided it should be safer (and more economical) to use the bag as a reservoir and empty it periodically without detaching it from the drainage tube and catheter. The infections that occurred in our patients during drainage into reservoir bags were attributable, for the most part, to invasion of the bladder by bacteria, especially $\mathrm{Pr}$. mirabilis, which passed along the outside of the catheter, probably because they were rather insen- sitive to the chlorhexidine that was used to exclude bacteria from this route.

Patients and nurses preferred the plastic bags to the glass drainage bottles, which ambulant patients found cumbersome. It remains to be seen how efficient the bags will be during longer periods of drainage and after prostatectomy, when it is sometimes necessary to irrigate the bladder.

\section{Summary}

Sterile disposable plastic bags with non-return valves were used for closed drainage of urine after gynaecological operations. It was found best to use the bag as a reservoir, joining it to the catheter before the patient left the theatre and not detaching it until the indwelling catheter was removed four days later. The bag was emptied periodically through an opening distal to the valve. Of 74 patients who were treated in this way, $17(23 \%)$ became infected. This was a slightly greater rate of infection than that observed during a previous period when bottles containing formaldehyde were used as receptacles. The infections probably were not attributable to faults in the drainage bag or valve, but to bacteria which passed from the urethra into the bladder outside the catheter, despite the precautions taken to exclude them.

We thank Eschmann Bros. and Walsh Ltd. for a supply of Meredith drainage bags.

\section{REFERENCES}

Dienes, L. (1946). Proc. Soc. exp. Biol. (N.Y.), 63, 265.

Gillespie, W. A., Lennon, G. G., Linton, K. B., and Slade, N. (1962). Brit. med. $., 2,13$.

- - Linton, K. B., Miller,

187.

Kippax, P. W. (1957). Ibid., 10, 211.

Kunin, C. M., and McCormack, R. C. (1966). New Engl. 9. Med., 274, 1155 .

Roberts, J. B. M., Linton, K. B., Pollard, B. R., Mitchell, J. P., and Gillespie, W. A. (1965). Brit. ł. Urol., 37, 63.

\section{Medical Memoranda}

\section{Methaqualone Addiction and Delirium Tremens}

Brit. med. F., 1967, 3, 92-93

Four cases of addiction to the non-barbiturate hypnotic methaqualone have been reported (Madden, 1966). The probability that these patients were physically dependent on methaqualone has been disputed (Martin, 1966) because of failure to show an abstinence syndrome. We now document another case, which was associated on withdrawal with the clinical syndrome of delirium tremens characteristic of the barbiturate-alcohol type of dependence.

\section{CASE Report}

A 47-year-old married man had suffered from rheumatoid arthritis since 1947. In turn he took increasing quantities of barbiturates (developing macrocytic anaemia), of an analgesic mixture containing phenacetin (developing nephrocalcinosis and renal tubular acidosis), of thalidomide (developing peripheral neuropathy), and later chloral hydrate.

For four years before admission he had been taking increasing doses of methaqualone, and for at least some months before admis- sion had taken neither alcohol nor any other drug. In the weeks prior to being admitted (January 1966) he was taking 60 150-mg. tablets of methaqualone daily.

He was found unconscious one evening (two days before admission) and his stocks of methaqualone were destroyed. Next evening he was restless and confused, and complained of seeing strangers in dark corners of the room.

On admission he was in delirium with obvious tremor. He was anxious and restless, and had visual hallucinations of which he was afraid. His temperature was $100^{\circ} \mathrm{F}$. $\left(37.8^{\circ} \mathrm{C}\right.$.), with brisk reflexes, and blood pressure 130/70. The liver was palpable $2 \mathrm{~cm}$. below the costal margin. A combination of promazine 600 mg. daily, phenobarbitone $1 \mathrm{~g}$. daily, and paraldehyde $10 \mathrm{ml}$. intramuscularly as required for states of agitation was only partially successful in controlling his restlessness and led to intoxication (with slurred speech, ataxia, and nystagmus). However, the administration of thioridazine (Melleril) in doses up to $800 \mathrm{mg}$. daily, starting on the fourth day, resulted in dramatic improvement and rapid recovery.

\section{Discussion}

Delirium tremens has not only been produced experimentally by withdrawal of addicting doses of barbiturates (Isbell et al., 1950) and alcohol (Isbell et al., 1955), but has now been recorded also with chloral hydrate, paraldehyde, glutethimide 